\title{
RECURSO EXTRAORDINARIO EN EL ESTADO DE ORIGEN. COMENTARIO A LA SENTENCIA DEL TRIBUNAL DE JUSTICIA DE LA UNIÓN EUROPEA, DE 17 DICIEMBRE 2015, IMTECH MARINE, C-300/14
}

\author{
REVIEW IN EXCEPTIONAL CASES IN THE MEMBER STATE \\ OF ORIGIN. JUDGMENT OF THE COURT (FOURTH CHAMBER) \\ OF 17 DECEMBER 2015, IMTECH MARINE, CASE C-300/14
}

\author{
JULIANA RODRÍGUEZ RODRIGO \\ Profesora Titular de Derecho Internacional Privado \\ Universidad Carlos III de Madrid \\ orcid ID: 0000-0002-5896-983X
}

Recibido: 00.00.2010 / Aceptado: 00.00.2010

DOI: https://doi.org/10.20318/cdt.2017.3899

\begin{abstract}
Resumen: El artículo 19 del Reglamento 805/2004, relativo al título ejecutivo europeo, es el precepto objeto de estudio por parte del Tribunal de Justicia en esta sentencia. En este artículo, el legislador europeo regula el recurso extraordinario contra la resolución por la cual se emite el título ejecutivo europeo. En este sentido, el precepto indicado establece la necesidad de que exista esta posibilidad de revisión de la resolución, en los casos en los que el deudor haya permanecido en rebeldía forzosa durante el procedimiento que ha dado lugar a la misma, y como requisito para que pueda ser certificada como título ejecutivo europeo la mencionada resolución. En relación con este artículo 19, el Tribunal de Luxemburgo aclara, entre otras cuestiones, que no es obligatorio para los Estados miembros del Reglamento regular en sus ordenamientos el recurso al que alude el precepto. Sin embargo, en el caso de que no exista esa posibilidad de revisión conforme a la legislación del foro, la resolución no podrá ser certificada como título ejecutivo europeo. Todo lo cual no significa que aquella no pueda circular por la Unión Europea, lo puede hacer, pero siempre que se acoja a otras normas aplicables en la materia, como el Reglamento 1215/2012.
\end{abstract}

Palabras clave: título ejecutivo europeo, recurso extraordinario.

Abstract: Article 19 of Regulation 805/2004, creating the European Enforcement Order, is the precept studied by the European Court in this judgment. In this article, the European legislator regulates the extraordinary appeal against the decision by which the European enforcement order is issued. The indicated article establishes the need for this possibility of revision of the resolution, in cases in which the debtor has remained in forced rebellion during the procedure, and as a requirement for that the resolution may be certified as the European Enforcement Order. In relation to this article 19, the Luxembourg Court clarifies, among other things, that it is not compulsory for the Member States to regulate in their legal systems this review. However, in the event that there is no such possibility of revision under the law of the forum, the resolution can not be certified as a European Enforcement Order. In these cases, the creditor may instead choose the system of recognition and enforcement under Regulation (EC) No 1215/2012 or other European instruments.

Keywords: European Enforcement Order, review in exceptional cases. 
Sumario: I. Hechos del caso. II. Cuestiones preliminares. 1. Notificación al deudor del procedimiento relativo al crédito. 2. Recurso extraordinario en el Estado de origen contra la resolución que certifica el TEE. III. Cuestiones planteadas. 1. Artículo 19. Obligación para los Estados miembros. 2. Plazos para interponer el recurso. 3. Órgano competente para emitir el certificado de TEE. IV. Conclusiones.

\section{Hechos del caso}

1. Esta sentencia del Tribunal de Justicia tiene su origen en una cuestión prejudicial planteada por el Tribunal de Apelación de Amberes. El órgano jurisdiccional remitente, básicamente, pregunta al Tribunal de Luxemburgo sobre el artículo 19 del Reglamento 805/2004 -RTEE, en adelante- ${ }^{1}$.

2. El caso objeto de la sentencia comentada parte de la existencia de un contrato de prestación de servicios, en virtud del cual, Imtech Marine prestó sus servicios a Radio Hellenic quien, a su vez, tenía la obligación de pagar una contraprestación económica por ello y no lo hizo. Debido al incumplimiento del pago, el prestador interpuso demanda ante el Tribunal de lo mercantil de Amberes reclamando el pago debido y solicitando que la resolución judicial dictada fuera certificada como TEE al amparo del Reglamento 805/2004.

De las dos peticiones formuladas, el Tribunal de Amberes estimó la primera y denegó la segunda. Respecto del incumplimiento del pago, el órgano jurisdiccional consideró que Radio Hellenic no había cumplido con las obligaciones a las que se había comprometido al concluir el contrato con Imtech y, por ello, la condenó a pagar la cantidad establecida. En el procedimiento seguido ante el Tribunal de Amberes, la demandada permaneció en rebeldía. En cuanto a la solicitud de certificación de la resolución judicial como título ejecutivo europeo -TEE, en adelante-, el órgano jurisdiccional concluyó que no podía hacer tal cosa porque el ordenamiento del foro no estaba adaptado al RTEE.

Ante la negativa del Tribunal de lo mercantil de Amberes de certificar como TEE la resolución judicial dictada, la parte demandante recurrió en apelación para solicitar aquello que le había sido denegado en primera instancia. El Tribunal de Apelación, a la vista de que el ordenamiento belga no regula el recurso extraordinario que recoge el artículo 19 del RTEE y, por lo tanto, no puede ofrecer esa posibilidad de recurrir al deudor, planteó una cuestión prejudicial al TJUE para preguntar, entre otras cuestiones, si el legislador belga está obligado a desarrollar en el ordenamiento del foro las prescripciones del artículo 19 del Reglamento.

\section{Cuestiones preliminares}

3. El Reglamento 805/2004 regula la creación de un título ejecutivo europeo para créditos no impugnados, que permita la libre circulación de resoluciones judiciales, de transacciones judiciales o de documentos públicos con fuerza ejecutiva, sin necesidad de ningún procedimiento intermedio de reconocimiento o ejecución en el Estado requerido (art. 1). El RTEE exige que el documento donde consta el crédito reúna una serie de requisitos que aparecen recogidos en el artículo $6 \mathrm{y}$, una vez cumplidos todos

\footnotetext{
${ }^{1}$ Reglamento 805/2004, del Parlamento Europeo y del Consejo, de 21 abril 2004, por el que se establece un título ejecutivo europeo para créditos no impugnados, DOUE L143, de 30 abril 2004, pp. 15-39.

Vid., entre otros, F.J. Garcimartín Alférez, El Título Ejecutivo Europeo, Thomson, Navarra, 2006; F. Ramos Romeu, El Título Ejecutivo Europeo, Thomson, Navarra, 2006; M. A. Rodríguez VÁzquez, El Título Ejecutivo Europeo, Colex, Madrid, 2005; F. Gascón Inchausti, El Título Ejecutivo Europeo para créditos no impugnados, Aranzadi, Navarra, 2005; M. A. RoDRÍGUEZ VÁzQUEZ, "El encaje del Título Ejecutivo Europeo en el Derecho procesal español”, en AAVV, Hacia la supresión del exequátur en el espacio judicial europeo: el título ejecutivo europeo, Universidad de Sevilla, 2006, pp. 193-217; P. BLANCOMorales Limones/A. Durán Ayago, "Luces y sombras del título ejecutivo europeo sobre créditos no impugnados" en A.L. Calvo Caravaca/S. Areal Ludeña (dirs.), Cuestiones actuales del Derecho mercantil internacional, Colex, Madrid, 2005, pp. 41-69; R. Gil Nievas/J. Carrascosa GonZÁlez, "Consideraciones sobre el Reglamento 802/2004, de 21 abril 2004, por el que se establece un título ejecutivo europeo para créditos no impugnados”, en A.L. CAlvo CARavaca/E. Castellanos Ruiz, La Unión Europea ante el Derecho de la globalización, Colex, Madrid, , pp. 371-400.
} 
ellos, se pueda certificar el documento como TEE a efectos de que sea ejecutado de forma automática en el resto de Estados de la Unión Europea -excepto Dinamarca- ${ }^{2}$.

\section{Notificación al deudor del procedimiento relativo al crédito}

4. Uno de esos requisitos para la certificación como título ejecutivo europeo es que el crédito haya sido notificado al deudor a través del escrito de incoación o documento equivalente (arts. 13 y 14). Así es, el legislador europeo permite la libre circulación del TEE certificado después de garantizar que el deudor -o su representante- ha tenido conocimiento de la existencia del proceso contra él, con tiempo suficiente para preparar su defensa ${ }^{3}$.

Por su parte, los artículos 16 y 17 regulan la información que se ha de proporcionar al deudor en este sentido. En efecto, se ha de informar de la existencia y contenido del crédito (art. 16) y de los requisitos procesales para impugnarlo (art. 17) ${ }^{4}$.

5. El TEE sólo se expide sobre créditos no impugnados, esto es, sobre créditos aceptados por el deudor o créditos sobre los que el deudor no manifiesta ninguna objeción (art. 3).

Esta condición ha sido criticada por la doctrina porque no entiende por qué los créditos impugnados, esto es, aquellos respecto de los cuales el deudor ha manifestado su oposición, una vez ha sido resuelto el procedimiento dentro del cual se han sustanciado, no pueden circular libremente por la Unión Europea; tal como ocurre con los no impugnados. En efecto, el objetivo del legislador europeo al respecto es que el deudor conozca de la existencia de un proceso relativo al crédito que exista contra él, y por ello exige el requisito de notificación, pero este objetivo no se ve truncado en ningún momento cuando

2 Todos los requisitos exigidos que se encuentran en el art. 6.1 del Reglamento son los siguientes: a) carácter ejecutivo de la resolución; b) respecto de ciertas normas de competencia por parte del Tribunal del Estado de origen; c) cumplimiento de las normas mínimas aplicables a los procedimientos; 4) domicilio del deudor en el Estado donde se ha emitido la resolución, en los supuestos en los que el deudor es consumidor (A.L. Calvo Caravaca/J. Carrascosa González, Derecho Internacional Privado, vol. I, 16a ed., Comares, Granada, 2016, p. 720; M. Y. Palomo Herrero, "Capítulo IV.1. Reconocimiento y ejecución de resoluciones judiciales en materia civil y mercantil. El Título Ejecutivo Europeo”, en M. JiMENo Bulnes (coord.), La cooperación judicial civil y penal en el ámbito de la Unión Europea, Bosch, Barcelona, 2007, pp. 141-147; R. GIL NIEVAS/J. Carrascosa GonzÁlez, "Consideraciones sobre el Reglamento 805/2004, de 21 abril 2004, por el que se establece un título ejecutivo europeo para créditos no impugnados", en A.-L. Calvo Caravaca/E. Castellanos Ruiz (dirs.), La Unión Europea ante el Derecho de la globalización, Colex, Madrid, 2008, pp. 387-393; M. A. RodríGUEz VázQuEz, Título ejecutivo europeo, Colex, Madrid, 2005, pp. 59-66; F.J. Garcimartín Alférez, Título Ejecutivo Europeo, Thomson, Navarra, 2006, pp. 111-149; F. Ramos Romeu, El Título Ejecutivo Europeo, Aranzadi, Navarra, 2006, pp. 41-71; F. Gascón Inchausti, El Título Ejecutivo Europeo para créditos no impugnados, Thomson, Navarra, 2005, pp. 107-145; M. A. RodRíguez VÁzQUEz, "El encaje del título ejecutivo europeo en el Derecho procesal español", en AA.VV, Hacia la supresión del exequátur en el espacio judicial europeo: el título ejecutivo europeo, Universidad de Sevilla, Sevilla, 2006, pp. 204-212).

3 Como acabamos de comentar, es posible notificar al representante del deudor, en virtud del artículo 15 del Reglamento y del Considerando 16, tanto al representante legal como a los representantes técnicos como abogado, procurador o graduado social (M. Y. Palomo Herrero, "Capítulo IV.1. Reconocimiento y ejecución de resoluciones judiciales en materia civil y mercantil. El Título Ejecutivo Europeo”, en M. JIMENo BuLNES (coord.), La cooperación judicial civil y penal en el ámbito de la Unión Europea, Bosch, Barcelona, 2007, p. 145; F. Gascón Inchausti, El Título Ejecutivo Europeo para créditos no impugnados, Thomson, Navarra, 2005, p. 124; R. Gil Nievas/J. Carrascosa González, "Consideraciones sobre el Reglamento 805/2004, de 21 abril 2004, por el que se establece un título ejecutivo europeo para créditos no impugnados", en A.-L. CALVO Caravaca/E. Castellanos Ruiz (dirs.), La Unión Europea ante el Derecho de la globalización, Colex, Madrid, 2008, p. 390)

4 A.L. Calvo Caravaca/J. Carrascosa González, Derecho Internacional Privado, vol. I, 16 a ed., Comares, Granada, 2016, p. 721; M. Y. Palomo Herrero, "Capítulo IV.1. Reconocimiento y ejecución de resoluciones judiciales en materia civil y mercantil. El Título Ejecutivo Europeo”, en M. JiMENo BuLNES (coord.), La cooperación judicial civil y penal en el ámbito de la Unión Europea, Bosch, Barcelona, 2007, pp. 145-146; R. Gil Nievas/J. CARrascosa González, "Consideraciones sobre el Reglamento 805/2004, de 21 abril 2004, por el que se establece un título ejecutivo europeo para créditos no impugnados”, en A.-L. Calvo Caravaca/E. Castellanos Ruiz (dirs.), La Unión Europea ante el Derecho de la globalización, Colex, Madrid, 2008, p. 388; M. A. Rodríguez Vázquez, Título ejecutivo europeo, Colex, Madrid, 2005, pp. 105-106; M. A. Rodríguez Vázquez, Título ejecutivo europeo, Colex, Madrid, 2005, pp. 59-66; F.J. Garcimartín AlfÉrez, Título Ejecutivo Europeo, Thomson, Navarra, 2006, pp. 149-151; F. Ramos Romeu, El Título Ejecutivo Europeo, Aranzadi, Navarra, 2006, pp. 69-71; F. Gascón InchausTi, El Título Ejecutivo Europeo para créditos no impugnados, Thomson, Navarra, 2005, pp. 134-141; M. A. RodríGUEZ VÁzQUEZ, "El encaje del título ejecutivo europeo en el Derecho procesal español", en AA.VV, Hacia la supresión del exequátur en el espacio judicial europeo: el título ejecutivo europeo, Universidad de Sevilla, Sevilla, 2006, pp. 211-212). 
hay una oposición al crédito por parte del deudor, porque, el hecho de que haya actuado así, impugnando el crédito, significa que ha tenido conocimiento de su existencia. Por lo tanto, no habría ningún motivo para no permitir que estos créditos impugnados también gozaran de la ejecución automática en los Estados de la Unión Europea - excepto Dinamarca- ${ }^{5}$.

\section{Recurso extraordinario en el Estado de origen contra la resolución que certifica el TEE}

6. La preocupación del legislador europeo por que el deudor sea informado de la existencia del proceso contra él, se mantiene en el supuesto de que el deudor haya permanecido en rebeldía forzosa, puesto que, en este caso, no hay certidumbre acerca de que haya conocido la existencia del procedimiento contra él. Esto es, aunque haya habido notificación, no hay garantía del conocimiento del crédito por su parte. Aun así, es posible certificar el TEE si el ordenamiento del Estado de origen ofrece la posibilidad de recurrir contra la resolución dictada (art. 19).

En efecto, para garantizar que el crédito reconocido en la resolución judicial sea no impugnado por parte del deudor, el legislador europeo debe exigir determinados requisitos adicionales en el supuesto en el que el deudor haya permanecido en rebeldía en el proceso y no haya podido, por tanto, manifestar su oposición al crédito. En concreto, el artículo 19 regula la necesidad de que esté previsto, en la legislación del Estado de origen, un recurso extraordinario contra el certificado del TEE, que garantice la oportunidad dada al deudor de impugnar el crédito reclamado frente a él ${ }^{6}$. En este sentido, se parte de la premisa de que el deudor ha permanecido en rebeldía forzosa en el procedimiento que ha dado lugar a la certificación del TEE.

7. Las circunstancias alternativas recogidas en el artículo 19.1 representan esa situación de rebeldía forzosa del deudor en el procedimiento que ha dado lugar a la certificación del TEE7 . Por ello, estas circunstancias son las siguientes:

a) que la notificación del documento de incoación del procedimiento o similar, o el de citación para una vista, se haya realizado según alguno de los métodos regulados en el artículo 14 del Reglamento, todos ellos sin acuse de recibo por parte del deudor. En este caso, también se debe cumplir que la notificación no se haya realizado con la suficiente antelación para que el deudor pudiera organizar su defensa, sin poder hacerle responsable de este hecho

b) "que el deudor no hubiera podido impugnar el crédito por razones de fuerza mayor o debido a circunstancias extraordinarias ajenas a su responsabilidad"

En ambos casos, el deudor es el que tiene que probar su actuación de buena fe y la imposibilidad de defenderse ${ }^{8}$.

Respecto del escenario planteado en la letra a), en relación con el primer requisito, la doctrina considera que la suficiente antelación con la que no se ha notificado al deudor la incoación del procedimiento debe ser entendida teniendo en cuenta que el tiempo que no ha sido suficiente debe empezar a contar, no desde el momento de la notificación, sino desde el momento en el que el deudor tiene conocimiento de la misma. Así es, en este supuesto la notificación no se realiza en la persona del deudor y, por ello, el tiempo empezará a contar desde el momento en que el deudor tiene conocimiento de ello y no desde el momento en que se practica la notificación (Considerando 14) ${ }^{9}$.

5 R. Gil Nievas/J. Carrascosa González, “Consideraciones sobre el Reglamento 805/2004, de 21 abril 2004, por el que se establece un título ejecutivo europeo para créditos no impugnados", en A.-L. Calvo Caravaca/E. Castellanos Ruiz (dirs.), $L a$ Unión Europea ante el Derecho de la globalización, Colex, Madrid, 2008, p. 386.

${ }^{6}$ La interposición del recurso puede suponer la suspensión del procedimiento de ejecución en el Estado requerido, según prescribe el artículo 23 del Reglamento.

7 F.J. Garcimartín Alférez, Título ejecutivo europeo, Thomson, Navarra, 2006, p. 156.

8 M. A. Rodríguez VÁzquez, "El encaje del título ejecutivo europeo en el Derecho procesal español", en AA.VV, Hacia la supresión del exequátur en el espacio judicial europeo: el título ejecutivo europeo, Universidad de Sevilla, Sevilla, 2006, p. 213; M. A. Rodríguez Vázquez, Título ejecutivo europeo, Colex, Madrid, 2005, p. 113.

9 F.J. Garcimartín Alférez, Título ejecutivo europeo, Thomson, Navarra, 2006, pp. 157-158. 


\section{Cuestiones planteadas}

\section{Artículo 19. Obligación para los Estados miembros}

8. Según el artículo 19, sólo podrá certificarse como título ejecutivo europeo la resolución judicial que pueda ser recurrida en el Estado de origen por el deudor rebelde, siempre que se cumplan varias circunstancias relacionadas con el procedimiento del recurso que estén previstas en el Derecho del foro. Esto significa, y es una de las cuestiones sobre las que se pronuncia el Tribunal de Justicia europeo, que si no se cumplen esas circunstancias en el Derecho nacional, no se podría certificar como título ejecutivo europeo la resolución judicial, y nada más, por lo tanto, el Estado de origen en cuestión no está obligado a regular en su ordenamiento las mencionadas circunstancias que aparecen en el artículo 19 (apartado 28) ${ }^{10}$. Así es, si no están previstas en el Derecho del foro, lo único que ocurre es que no se podrá certificar la resolución judicial como título ejecutivo europeo, no obstante lo cual, dicha resolución judicial podría ser reconocida o ejecutada en otro Estado europeo en virtud del procedimiento previsto en el Reglamento 1215/2012 (art. 27).

En este sentido, el Reglamento 1215/2012 es compatible en su aplicación con el RTEE, de este modo, teniendo en cuenta ambos textos, el acreedor tendría varias opciones al respecto. Por un lado, puede solicitar el certificado de TEE y conseguir la ejecución automática del mismo en cualquier Estado de la Unión Europea - excepto Dinamarca-. En segundo lugar, puede optar por la aplicación del Reglamento Bruselas I bis y solicitar la ejecución del documento en el Estado requerido. En este caso, si no concurre ningún motivo de denegación, se ejecutará el documento. Por último, puede iniciar simultáneamente ambos procesos ${ }^{11}$.

\section{Plazos para interponer el recurso}

9. El Tribunal de Luxemburgo interpreta que, según el artículo 19, el juez del Estado de origen podrá certificar una resolución judicial como título ejecutivo europeo siempre que en el Derecho del foro se prevea la posibilidad de revisión plena de la resolución, tanto desde el punto de vista jurídico como desde el fáctico, en los supuestos planteados en el apartado 1 del precepto (apartado 38). En efecto, el recurso extraordinario debe permitir la revisión plena, tal como prescribe el artículo 18.1.b) del RTEE ${ }^{12}$.

En relación con esto, el Tribunal europeo dispone que el deudor debe poder recurrir "más allá de los plazos ordinarios establecidos por el Derecho nacional para formular oposición o interponer recurso contra la resolución" (apartado 39).

10. En el caso estudiado, el Tribunal de Amberes también pregunta sobre los plazos para interponer recurso existentes en el Derecho belga, todo ello porque esos plazos pueden acabar antes de que el deudor conozca de la existencia de la resolución sobre el crédito y, por tanto, antes de que pueda recurrirla.

Pues bien, el Tribunal afirma que para que la legislación del foro cumpla con las prescripciones recogidas en el artículo 19, debe permitir al deudor acogerse a la posibilidad de prorrogar los plazos de interposición del recurso y no regirse, por tanto, por los plazos ordinarios existentes, si aquellos le son más favorables. De tal forma que, si en el Derecho del foro existe esta posibilidad de prorrogar plazos de modo que no comiencen a correr hasta que el deudor conozca de la existencia de la resolución, esos plazos deben ser los aplicados al mismo (apartado 39).

10 A.L. Calvo Caravaca/J. Carrascosa González, Derecho Internacional Privado, vol. I, $16^{\mathrm{a}}$ ed., Comares, Granada, 2016, p. 722; E. Martín, "Paso de gigante en la Justicia europea. El título ejecutivo europeo", Escritura Pública, 2004, p. 28; A. Fernández-Tresguerres, "La escritura pública notarial: un título ejecutivo europeo”, Escritura Pública, 2004, p. 29; R. GIL Nievas/J. Carrascosa GonzÁlez, "Consideraciones sobre el Reglamento 805/2004, de 21 abril 2004, por el que se establece un título ejecutivo europeo para créditos no impugnados”, en A.-L. Calvo Caravaca/E. Castellanos Ruiz (dirs.), La Unión Europea ante el Derecho de la globalización, Colex, Madrid, 2008, p. 375-376; M. A. RodríGuEz VÁzquez, El título ejecutivo europeo, Colex, Madrid, 2005, p. 67; M. A. Rodríguez VÁzquez, Título ejecutivo europeo, Colex, Madrid, 2005, pp. 83-84.

11 F.J. Garcimartín Alférez, Título Ejecutivo Europeo, Thomson, Navarra, 2006, pp. 102-103; F. Ramos Romeu, El Título Ejecutivo Europeo, Aranzadi, Navarra, 2006, pp. 37-40; F. GAScón Inchausti, El Título Ejecutivo Europeo para créditos no impugnados, Thomson, Navarra, 2005, p. 34

12 F.J. Garcimartín AlfÉrez, Título ejecutivo europeo, Thomson, Navarra, 2006, p. 157 


\section{C. Órgano competente para emitir el certificado de TEE}

11. En último lugar, el Tribunal de Justicia se pronuncia acerca del órgano que debería emitir el certificado de TEE y el momento en el que debe solicitarse la certificación.

12. Respecto de lo primero, en concreto, no se refiere a la competencia para dictaminar que la resolución judicial puede ser certificada como TEE, sino a la competencia para emitir ese certificado.

Empezando por lo general, el RTEE menciona que el tribunal competente para certificar el título ejecutivo europeo es aquel que conozca del asunto en el momento de cumplirse los requisitos previstos en las letras a), b) o c) del apartado 1 del artículo 3. No dice nada respecto de que este tribunal deba ser el mismo que ha emitido la resolución judicial sobre la que se solicita la certificación como TEE, por lo tanto, ambos órganos podrían ser distintos. En Derecho español, no obstante, el mismo órgano que ha emitido la resolución será el competente para expedir el certificado del TEE ${ }^{13}$.

Volviendo a la sentencia que estamos comentando, en relación con el órgano que puede llevar a cabo el acto formal de expedición del certificado del TEE, el RTEE no especifica qué órgano tiene esta competencia (apartado 44). El Tribunal europeo considera que, si bien la certificación propiamente dicha sólo puede ser declarada por el juez, porque es él quien debe analizar si se cumplen los requisitos exigidos por el RTEE, el acto formal de expedición de la certificación puede realizarlo el secretario judicial (apartados 46 y 45$)^{14}$.

13. Para finalizar, el momento en el que se ha de solicitar la certificación del TEE puede ser cualquiera (apartado 48). Exigir que ese momento sea el de interposición del escrito de incoación del procedimiento no tiene sentido porque a esas alturas del proceso no se sabe si el crédito va a ser impugnado o no y, por tanto, si va a poder ser certificado como TEE (apartado 49) ${ }^{15}$. Por lo tanto, en el caso objeto de la sentencia, el prestador del servicio no tenía por qué haber hecho la solicitud del certificado de TEE en el momento del escrito de incoación del procedimiento, como así hizo.

\section{Conclusiones}

14. En este caso Imtech, el Tribunal de Justicia aprovecha la ocasión planteada para resolver algunas dudas que suscita la interpretación del artículo 19 del RTEE. En concreto, responde a la pregunta de si los Estados miembros están obligados a tener regulado en sus ordenamientos el recurso de revisión al que alude el precepto citado y, por otro lado, también dispone qué autoridades son competentes para expedir el certificado en el que consta el TEE.

15. En relación con lo primero, el órgano judicial europeo considera que no existe una exigencia para los Estados miembros en relación con recoger este recurso de revisión en sus ordenamientos. Esto es, los legisladores nacionales pueden tenerlo, en cuyo caso, este no sería un motivo para no certificar como TEE cualquier resolución judicial o transacción que cumpla el resto de requisitos exigidos por el Reglamento. Pero, también pueden no tener regulado en sus ordenamientos este recurso de revisión. En este escenario, la resolución no podría certificarse como TEE pero podría, también, circular por la Unión Europea acogiéndose, eso sí, a otras normas aplicables como el Reglamento 1215/2012.

13 Disposición Final Vigésimo Primera de la LEC (Ley 1/2000, de 7 de enero, BOE núm. 7, de 8 de enero 2000). Vid., en este sentido, entre otros, F. GASCón Inchausti, El Título Ejecutivo Europeo para créditos no impugnados, Thomson, Navarra, 2005, p. 224; F.J. Garcimartín Alférez, Título ejecutivo europeo, Thomson, Navarra, 2006, pp. 114-115.

Algún autor considera que la referencia del artículo 6.1 en relación con el órgano jurisdiccional de origen implica que será esté ante quien se deba hacer la solicitud, lo cual no implica que sea él quien la resuelva (F. RAmos Romeu, El Título Ejecutivo Europeo, Aranzadi, Navarra, 2006, p. 109; F.J. Garcimartín Alférez, Título Ejecutivo Europeo, Thomson, Navarra, 2006, p. 112).

14 Será el Derecho nacional el que lo determine (F.J. Garcimartín AlfÉrez, Título ejecutivo europeo, Thomson, Navarra, 2006, p. 112)

${ }^{15}$ La alusión a en cualquier momento del artículo 6.1 RTEE debe interpretarse en el sentido de en cualquier momento a partir de la existencia de la resolución o el documento que se quieran certificar (F. RAmos Romeu, El Título Ejecutivo Europeo, Aranzadi, Navarra, 2006, p. 109) 
En este sentido, en España no hay unanimidad a la hora de determinar si existe o no en nuestro ordenamiento esta posibilidad de revisar la resolución donde se certifica el TEE en los casos previstos en el artículo 19 del RTEE. Si bien hay autores que consideran que el art. 501 de la Ley de Enjuiciamiento Civil -LEC, en adelante-, al regular la rescisión de sentencia firme a instancias del rebelde, recoge ese procedimiento de revisión al que alude el artículo 19 RTEE, hay otros que entienden que el precepto citado de la LEC es válido para los casos recogidos en la letra b) del artículo 19 RTEE, esto es, para cuando "el deudor no hubiere podido impugnar el crédito por razones de fuerza mayor o debido a circunstancias extraordinarias ajenas a su responsabilidad", pero no para los supuestos de la letra a) ${ }^{16}$.

16. Respecto a la autoridad que puede expedir físicamente el TEE, el Tribunal de Luxemburgo dispone que eso lo debe decidir el legislador nacional y que, en ese sentido, podría ser el secretario judicial quien se encargue del acto formal de expedición.

En el ordenamiento español, teniendo en cuenta que los secretarios judiciales -actuales letrados de la administración de justicia- cuentan entre sus funciones con la de expedir "certificaciones o testimonios de las actuaciones judiciales no declaradas secretas ni reservadas a las partes, con expresión de su destinatario y el fin para el cual se solicitan”, podrían ser ellos quienes se encarguen de la realización de este acto formal de expedición del TEE (art. 453.2 LOPJ).

${ }^{16}$ A favor de que el procedimiento del artículo 501 LEC permite al deudor revisar la resolución en aplicación del artículo 19 RTEE, vid., F.J. Garcimartín Alférez, Título ejecutivo europeo, Thomson, Navarra, 2006, pp. 159-160. En contra, vid., F. Ramos Romeu, El Título Ejecutivo Europeo, Aranzadi, Navarra, 2006, pp. 77-79. Por su parte, F. Gascón Inchausti, si bien entiende que todos los supuestos que recoge el artículo 19 RTEE no están contempladas en el artículo 501 LEC, existen otros procedimientos en nuestro ordenamiento que permiten concluir que en España se cumplen las normas mínimas para la revisión en casos excepcionales del artículo 19 RTEE (F. Gascón Inchausti, El Título Ejecutivo Europeo para créditos no impugnados, Thomson, Navarra, 2005, pp. 145-151.

Artículo 501 LEC: "Los demandados que hayan permanecido constantemente en rebeldía podrán pretender, del tribunal que la hubiere dictado, la rescisión de la sentencia firme en los casos siguientes:

$1 .^{\circ}$ De fuerza mayor ininterrumpida, que impidió al rebelde comparecer en todo momento, aunque haya tenido conocimiento del pleito por haber sido citado o emplazado en forma.

2. ${ }^{\circ}$ De desconocimiento de la demanda y del pleito, cuando la citación o emplazamiento se hubieren practicado por cédula, a tenor del artículo 161, pero ésta no hubiese llegado a poder del demandado rebelde por causa que no le sea imputable.

3. ${ }^{\circ}$ De desconocimiento de la demanda y del pleito, cuando el demandado rebelde haya sido citado o emplazado por edictos y haya estado ausente del lugar en que se haya seguido el proceso y de cualquier otro lugar del Estado o de la Comunidad Autónoma, en cuyos Boletines Oficiales se hubiesen publicado aquéllos”. 